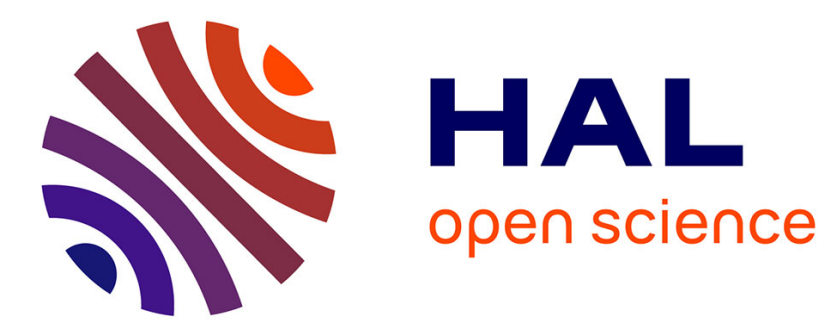

\title{
Indirect effects of lightning on aircraft engine
}

\author{
P. Aguilera, C. Lair, F. Issac, B. Michielsen, M. Hélier, M. Darces
}

\section{To cite this version:}

P. Aguilera, C. Lair, F. Issac, B. Michielsen, M. Hélier, et al.. Indirect effects of lightning on aircraft engine. ICOLSE 2015, Sep 2015, TOULOUSE, France. hal-01521957

\section{HAL Id: hal-01521957 \\ https://hal.science/hal-01521957}

Submitted on 12 May 2017

HAL is a multi-disciplinary open access archive for the deposit and dissemination of scientific research documents, whether they are published or not. The documents may come from teaching and research institutions in France or abroad, or from public or private research centers.
L'archive ouverte pluridisciplinaire HAL, est destinée au dépôt et à la diffusion de documents scientifiques de niveau recherche, publiés ou non, émanant des établissements d'enseignement et de recherche français ou étrangers, des laboratoires publics ou privés. 


\title{
INDIRECT EFFECTS OF LIGHTNING ON AIRCRAFT ENGINE
}

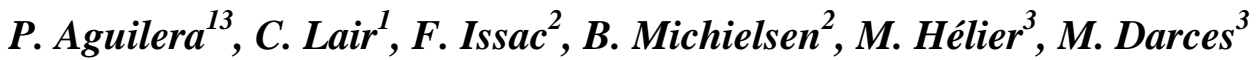 \\ ${ }^{\text {I} S N E C M A ~ V i l l a r o c h e, ~ F r a n c e, ~ p a u l a . a g u i l e r a @ s n e c m a . f r, ~ c y r i l . l a i r @ s n e c m a . f r, ~}$ \\ 2ONERA DEMR, Toulouse, France, francois.issac@onera.fr, bastiaan.michielsen@onera.fr, \\ ${ }^{3}$ Sorbonne Universités, UPMC Univ Paris 06, UR2, L2E, F-75005, Paris, France, \\ marc.helier@upmc.fr, muriel.darces@upmc.fr
}

Keywords: Lightning Simulation, Macro-Modelling, Patch Finite Elements

\section{Abstract}

This paper presents a new approach for simulating the indirect effects of a lightning impact on an aircraft engine.

Based on macro-modelling, it performs a model reduction, in a similar way as "stick models", but using a patch support instead. This new macro finite element space allows for fast resolution of the quasi-static lightning injection problem.

\section{Introduction}

Due to a reduced design time, numerical simulation plays a major role from the specification to the certification of an aircraft engine regarding indirect effects of lightning [1].

On the one hand, 3D solvers, based on the resolution of discretized Maxwell's equations, can be used to predict precisely the constraints to be applied to equipments in a complex system, and therefore be a part of lightning certification process. However, they involve heavy tools which are not optimized for quick parameters optimization or measurement analysis, as they require lengthy computations, even with using a powerful parallel computer.

On the other hand, much lighter models such as "stick models" have gained a lot of interest [2]. Based on the PEEC (Partial Element Equivalent Circuit) method, they have shown to be faster and sufficiently accurate in some aeronautical applications. One drawback though is the poor estimation of the current distribution at higher frequencies as current is constrained to follow the stick path.

A new model, based on macro-modelling, has been implemented to overcome this problem.

\section{Method}

\subsection{Macro-modelling for lightning simulation}

Assuming the quasi-static behavior of the phenomena, lightning current distribution can be expanded in a macro finite element space. Each macro finite element is locally curl-free with a constant divergence $Q$ over a triangulated support called "patch" [3].

$$
\begin{gathered}
\nabla_{s} \cdot \boldsymbol{j}=\frac{\partial}{\partial \mathrm{x}} j_{\mathrm{x}}+\frac{\partial}{\partial \mathrm{y}} j_{y}=Q \\
\nabla_{s} \times \boldsymbol{j}=\left(\frac{\partial}{\partial \mathrm{y}} j_{\mathrm{x}}-\frac{\partial}{\partial \mathrm{x}} j_{y}\right) \hat{\mathbf{z}}=\mathbf{0}
\end{gathered}
$$

Formulation (1) can be discretized in a 1-skeleton of the simplicial complex dual to the triangulation of the patch (Figure 1).

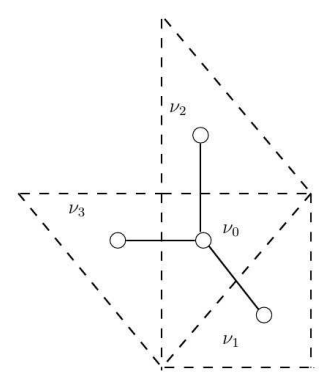

Figure 1. Simplicial complex dual of a triangulation

As $\boldsymbol{j}_{\boldsymbol{k}}$ can be written as the gradient of a potential: $\boldsymbol{\nabla} \varphi_{k}$, (1) becomes:

$$
\begin{gathered}
\left.\Delta \varphi_{k}\right|_{i}=-\frac{1}{N_{P}} \\
\left.\nabla \varphi_{k} \cdot \widehat{\boldsymbol{n}}\right|_{i}=\left\{\begin{array}{l}
-\frac{1}{\mathrm{~N}_{\partial_{\mathrm{k}} \mathrm{P}}} \text { if } \mathrm{i} \in \partial_{\mathrm{k}} \mathrm{P}, \\
0 \quad \text { if } \mathrm{i} \in \partial \mathrm{P}-\partial_{\mathrm{k}} \mathrm{P}
\end{array}\right.
\end{gathered}
$$

where $N_{P}$ represents the number of cells of patch P, and $N_{\partial_{k} P}$ the number of cells defining boundary $\partial_{k} P$ (see Figure 2). This Poisson-Neumann problem (2) is solved by using the surface mesh Laplace operator [4]. Its coefficients are given by the formulas:

$$
\left.\Delta \varphi\right|_{i i}=\frac{4}{\bar{d}_{l}} \cdot \overline{\left(\frac{1}{d_{l}}\right)}
$$




$$
\left.\Delta \varphi\right|_{i j}=\left\{\begin{array}{c}
-\frac{4}{\bar{d}_{\imath}} \cdot \frac{1}{N_{i} d_{i j}} \text { if } j \in V(i) \\
0, \text { else }
\end{array}\right.
$$

where

$$
\begin{aligned}
\bar{d}_{\imath} & =\frac{1}{N_{i}} \sum_{j \in V(i)} d_{i j} \\
\left(\frac{\overline{1}}{d_{l}}\right) & =\frac{1}{N_{i}} \sum_{j \in V(i)} \frac{1}{d_{i j}} \\
N_{i} & =\operatorname{dim}(V(i))
\end{aligned}
$$

$d_{i j}$ being the distance between nodes $i$ and $j$.

This operator enables the interpolation between a limited set of boundary currents and the control of the obtained current density's divergence by imposing a constant charge density equal to $-\frac{1}{N_{P}}$ (see [5] for alternative techniques).

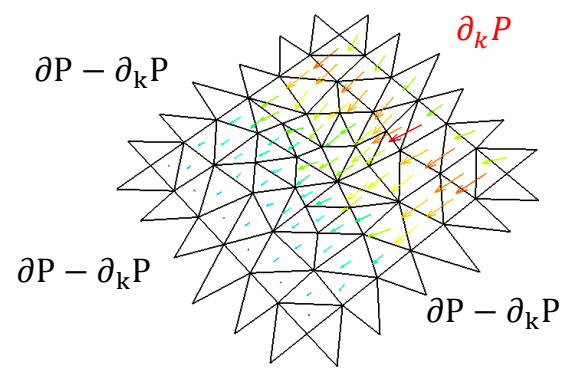

Figure 2. A macro finite element on a patch

Once these current distributions have been constructed, one can compute the associated model coefficients with:

$$
\begin{gathered}
L_{p q}=\int \boldsymbol{j}_{p} \cdot \boldsymbol{A}\left(\boldsymbol{j}_{q}\right)=\int \boldsymbol{j}_{p}(\boldsymbol{r}) \cdot \int G\left(\boldsymbol{r}, \boldsymbol{r}^{\prime}\right) \boldsymbol{j}_{q} \\
C^{-1}{ }_{p q}=\int \rho_{p} \cdot \varphi\left(\rho_{q}\right)=\int \rho_{p}(\boldsymbol{r}) \cdot \int G\left(\boldsymbol{r}, \boldsymbol{r}^{\prime}\right) \rho_{q} \\
R_{p q}=\int j_{p} . Z_{s} j_{q}
\end{gathered}
$$

where $\boldsymbol{j}_{\boldsymbol{p}}$ is a macro element, with $\mathrm{p}=1, \ldots, \mathrm{N}, \mathrm{N}$ being the total number of degrees of freedom of the entire configuration. The constant $Z_{s}$ is the surface impedance of the patch and $\rho_{q}=\operatorname{div} \boldsymbol{j}_{q}$. In this formulation, a static approximation of the Green's Function is assumed:

$$
G\left(\boldsymbol{r}, \boldsymbol{r}^{\prime}\right) \approx \frac{1}{4 \pi\left|\boldsymbol{r}-\boldsymbol{r}^{\prime}\right|}
$$

\subsection{Sensitivity analysis of mesh on components}

Different sources of error can be enumerated for this macro model:

The Galerkin representation of the components.
- The relaxation method used to implement the Laplace operator.

- The static approximation of the Green's function.

The inputs of the model, e.g. the number of cells of the triangulation and the type of mesh used (structured, unstructured, regular and irregular) will have an impact on the resulting coefficients.

As an example, let us consider a squared plate (length $l=1 \mathrm{~m}$, width $w=1 \mathrm{~m}$ ) over which 2 orthogonal distributions circulate (Figure 3). The conductivity $\sigma$ is set to $4000 \mathrm{~S} / \mathrm{m}$ and its depth $e$ to $5 \mathrm{~mm}$.

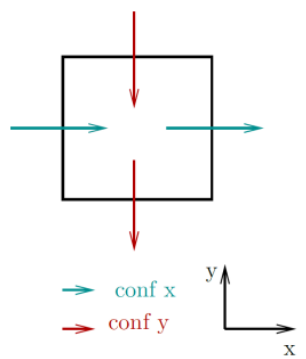

Figure 3. Two orthogonal distributions over a squared plate

The theoretical resistance and self-inductance of a uniform distribution in a plate are given by [6]:

$$
\begin{gathered}
R=Z_{s}=\frac{1}{\sigma e}=0,05 \Omega \\
L \approx \frac{\mu_{0}}{2 \pi}\left(\ln \left(\frac{2 l}{w_{e q}}\right)-1+\frac{w_{e q}}{l}\right)=2,83 \cdot 10^{-7} \mathrm{H}
\end{gathered}
$$

where $w_{e q}=0.447 \cdot \frac{w+e}{2}$.
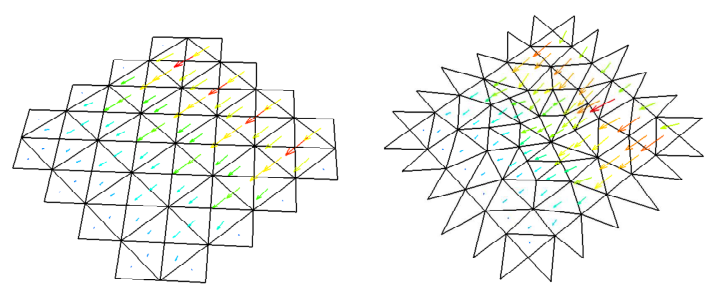

Figure 4. Squared plate. Left: structured mesh, Right: unstructured mesh

\begin{tabular}{|l|c|c|c|c|c|}
\hline $\mathrm{Nb}$ of cells & $R_{x}$ & $R_{y}$ & Error $\mathrm{x}$ & Error $\mathrm{y}$ & Asymmetry \\
\hline $16-l / 2$ & $42 \mathrm{~m} \Omega$ & $42 \mathrm{~m} \Omega$ & $16.0 \%$ & $16.0 \%$ & $0 \%$ \\
\hline $64-l / 4$ & $46 \mathrm{~m} \Omega$ & $46 \mathrm{~m} \Omega$ & $8.0 \%$ & $8.0 \%$ & $0 \%$ \\
\hline $256-l / 8$ & $49,3 \mathrm{~m} \Omega$ & $49,3 \mathrm{~m} \Omega$ & $1.4 \%$ & $1.4 \%$ & $0 \%$ \\
\hline
\end{tabular}

Table 1. Resistance of the two current distributions along $x$ and $y$ over a structured mesh for different numbers of cells 


\begin{tabular}{|l|c|c|c|c|c|}
\hline Nb of cells & $L_{x}$ & $L_{y}$ & Error x & Error y & Asymmetry \\
\hline $16-l / 2$ & $0.22 \mu \mathrm{H}$ & $0.22 \mu \mathrm{H}$ & $22.2 \%$ & $22.2 \%$ & $0 \%$ \\
\hline $64-l / 4$ & $0.26 \mu \mathrm{H}$ & $0.26 \mu \mathrm{H}$ & $8.1 \%$ & $8.1 \%$ & $0 \%$ \\
\hline $256-l / 8$ & $0.287 \mu \mathrm{H}$ & $0.287 \mu \mathrm{H}$ & $1.4 \%$ & $1.4 \%$ & $0 \%$ \\
\hline
\end{tabular}

Table 2. Self-inductance of the two current distributions along $x$ and $y$ over a structured mesh for different numbers of cells

\begin{tabular}{|l|c|c|c|c|c|}
\hline $\mathrm{Nb}$ of cells & $R_{x}$ & $R_{y}$ & Error x & Error y & Asymmetry \\
\hline $16-l / 2$ & $40 \mathrm{~m} \Omega$ & $40 \mathrm{~m} \Omega$ & $20.6 \%$ & $20.6 \%$ & $0 \%$ \\
\hline $64-l / 4$ & $46 \mathrm{~m} \Omega$ & $46 \mathrm{~m} \Omega$ & $8.0 \%$ & $8.0 \%$ & $0 \%$ \\
\hline $256-l / 8$ & $47.4 \mathrm{~m} \Omega$ & $47.5 \mathrm{~m} \Omega$ & $5.2 \%$ & $5.0 \%$ & $0.2 \%$ \\
\hline
\end{tabular}

Table 3. Resistance of the two current distributions along $x$ and $y$ over an unstructured mesh for different numbers of cells

\begin{tabular}{|c|c|c|c|c|c|}
\hline Nb of cells & $L_{x}$ & $L_{y}$ & Error x & Error y & Asymmetry \\
\hline $16-l / 2$ & $0.21 \mu \mathrm{H}$ & $0.21 \mu \mathrm{H}$ & $25.7 \%$ & $25.7 \%$ & $0 \%$ \\
\hline $64-l / 4$ & $0.25 \mu \mathrm{H}$ & $0.25 \mu \mathrm{H}$ & $11.7 \%$ & $11.7 \%$ & $0 \%$ \\
\hline $256-l / 8$ & $0.274 \mu \mathrm{H}$ & $0.274 \mu \mathrm{H}$ & $3.2 \%$ & $2.5 \%$ & $0.7 \%$ \\
\hline
\end{tabular}

Table 4. Self-inductance of the two current distributions along $x$ and $y$ over an unstructured mesh for different numbers of cells
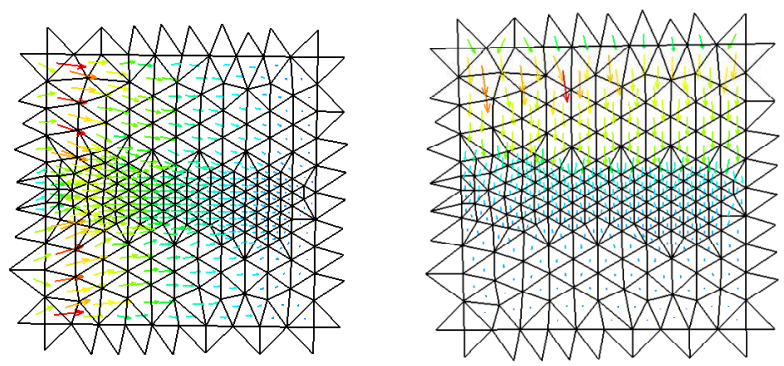

Figure 5. Current distribution on an irregular unstructured mesh, left: along $\mathrm{x}$, right: along y

\begin{tabular}{|l|c|c|c|c|c|}
\hline Nb of cells & $R_{x}$ & $R_{y}$ & Error x & Error y & Asymmetry \\
\hline $256-l / 8$ & $54 \mathrm{~m} \Omega$ & $47.7 \mathrm{~m} \Omega$ & $8.2 \%$ & $4.6 \%$ & $13.4 \%$ \\
\hline
\end{tabular}

Table 5. Resistance of the two current distributions along $x$ and $y$ over an unstructured irregular mesh

\begin{tabular}{|l|c|c|c|c|c|}
\hline $\mathrm{Nb}$ of cells & $L_{x}$ & $L_{y}$ & Error $\mathrm{x}$ & Error y & Asymmetry \\
\hline $256-l / 8$ & $0.295 \mu \mathrm{H}$ & $0.274 \mu \mathrm{H}$ & $4.2 \%$ & $3.2 \%$ & $8.7 \%$ \\
\hline
\end{tabular}

Table 6. Self-inductance of the two current distributions along $x$ and $y$ over an unstructured irregular mesh

Tables 1 and 2 show the sensitivity on coefficients $\mathrm{R}$ and $\mathrm{L}$ to the number of cells. When this number increases, the error associated to the Galerkin representation decreases. Tables 3 and 4 assess the influence of the mesh structure on the results (see Figure 4). For an unstructured mesh, the dual nodes of a triangulation are not distributed at regular angles which is one of the requirements for the relaxation method used to solve (3).

Finally, Table 5 and 6 show the impact of irregular distances between neighbours (see Figure 5). When the irregularity is along the equipotential lines, the error remains unchanged with respect to an unstructured regular mesh.

The analysis of the error associated to a static approximation of the Green's function is presently work in process.

\subsection{Numerical method}

Besides this model, a global method for lightning simulation has been proposed which comprises several steps.

Step 1 concerns the identification of contact resistances in the engine Digital Mock-Up (DMU) (see Figure 6).

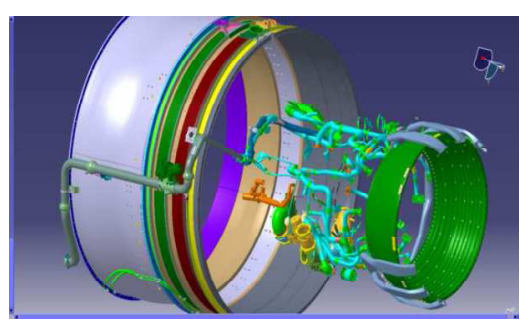

Figure 6. Digital Mock-Up of some constitutive elements of an aircraft engine

The electrical interconnections between each conductor of the engine define a first partitioning of the interaction configuration. This partitioning delimitates complex modules such as harnesses, structures and equipments. The triangulation of each module can easily reach several millions of cells. The full-wave resolution may require a long time (typically more than ten hours on a multi-processors (256) computer, with a limited time range (typically $50 \mu \mathrm{s}$ ). As the aim of this study is the implementation of a numerical method for fast resolution, a geometric surface smoothing can be applied in order to reduce the number of micro finite elements.

Step 2 is based on geometric surface smoothing of complex conductors. The characteristic dimension of an aircraft engine is 5 meters, which is small compared to the minimal wavelength of lightning (30 meters). Therefore, as long as electrical interconnections are preserved, a reduction of the number of cells will have little impact on the results.

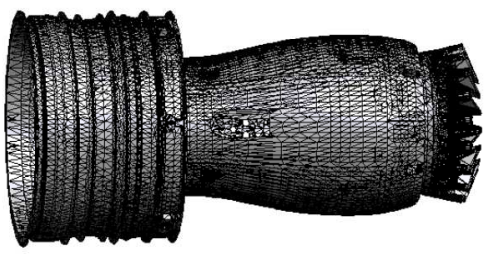




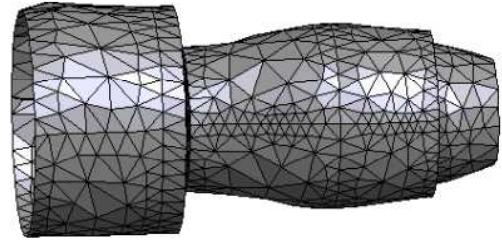

Figure 7. Mesh reduction of part of an engine: top: 400000 cells, bottom: 2000 cells

Figure 7 shows a mesh reduction applied to some structural parts of the engine.

Once all the modules have been simplified, one has to specify the final partitioning of the system, which constitutes the next step.

Step 3: The final partitioning can be done automatically over domains which are simply connected using the spectral resolution of the Laplace operator (see [7]). A binary tree is then filled with subdivisions.

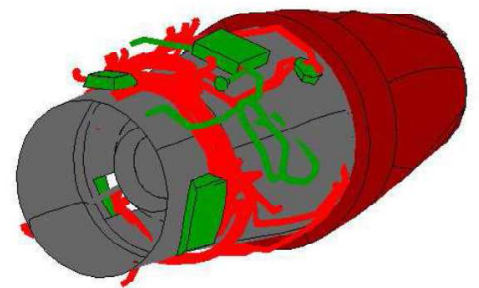

Figure 8. Partitioning applied to an engine after steps 1 and 2

Finally, the current distributions are implemented for each patch defined in Figure 8.

\subsection{Tests set-up}

The numerical method presented in this paper has been applied to a cylinder made of composite material covered by several harnesses over which tests in Continuous Wave (CW) have been run.

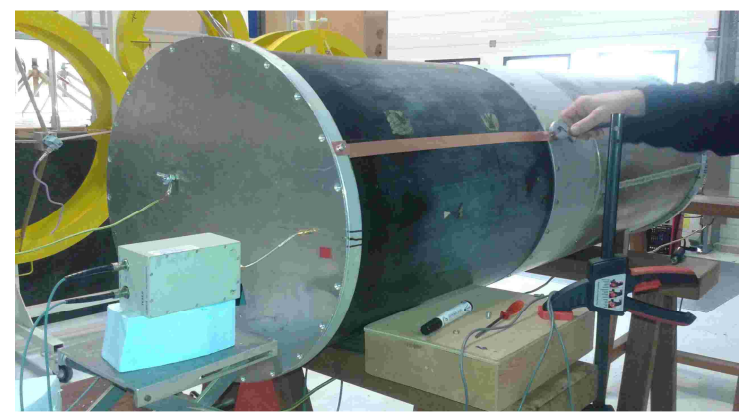

Figure 9. Test set-up
The system under test is placed on a wooden structure (Figure 9). The material composition is depicted in Figure 10 and the injection configuration for the CW analysis in Figure 11.

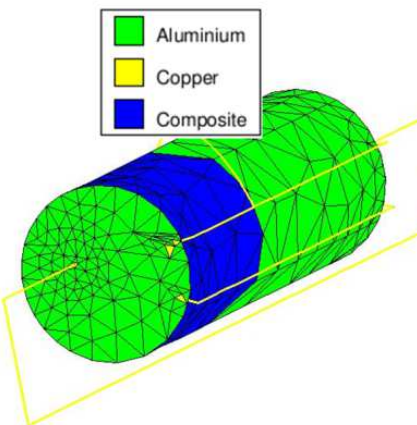

Figure 10. Materials

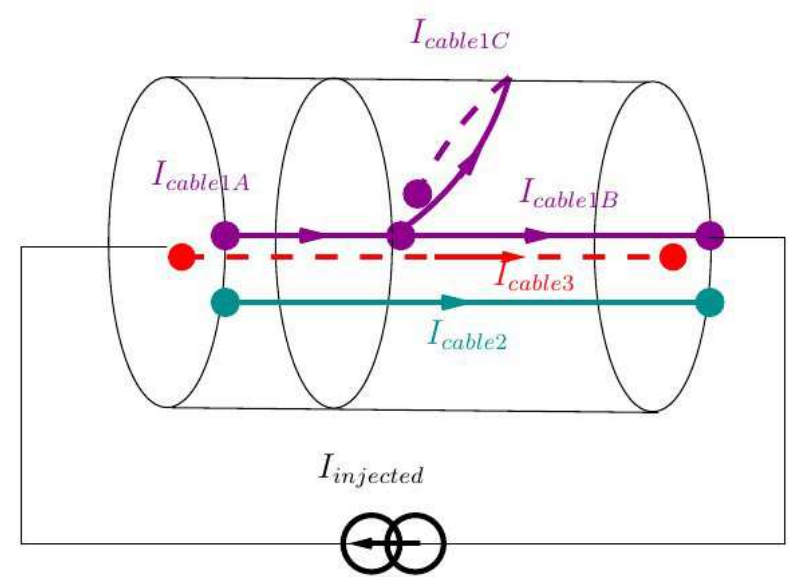

Figure 11. Lightning injection configuration

The initial partitioning proposed in Figure 12 is based on the analysis of the electrical interconnections between conductors and the materials distribution in the system. This partitioning leads to a network with the pertinent degrees of freedom to obtain a good correspondence with measurements at low frequency, as it will be shown in section 4 .

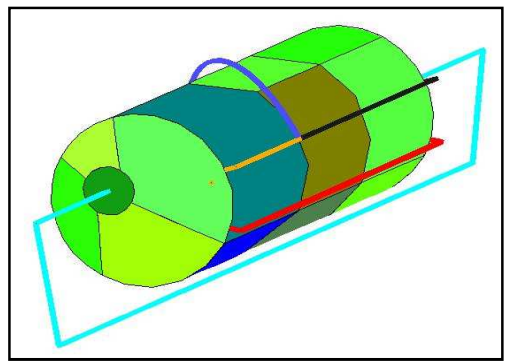

Figure 12. Low frequency partitioning 


\section{Results}

\subsection{Low frequency partitioning}

The calculation of the macro impedance matrix associated to the partitioning in Figure 12 takes only 30 seconds for 2000 cells in the triangulation and 20 patches. The circuit equation is solved in 1 second.

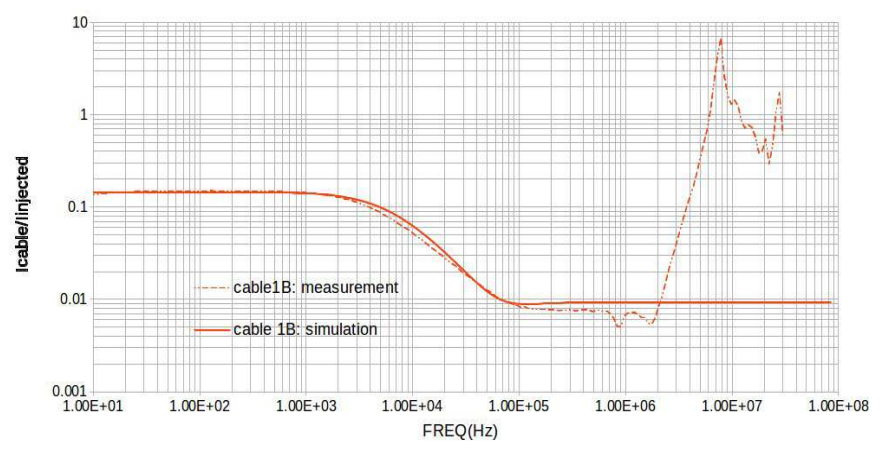

Figure 13. CW analysis of normalized current over cable 1B (see Figure 11), continuous: simulation, dashed: measurement

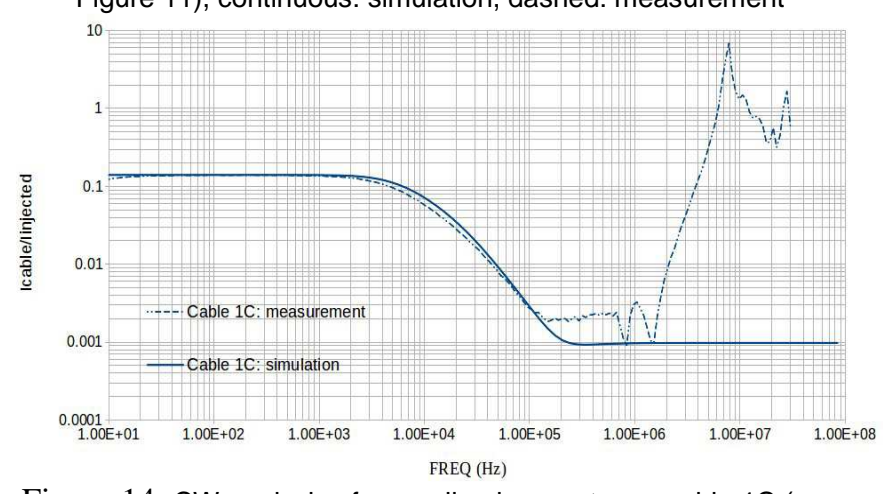

Figure 14. CW analysis of normalized current over cable 1C (see Figure 11), continuous: simulation, dashed: measurement

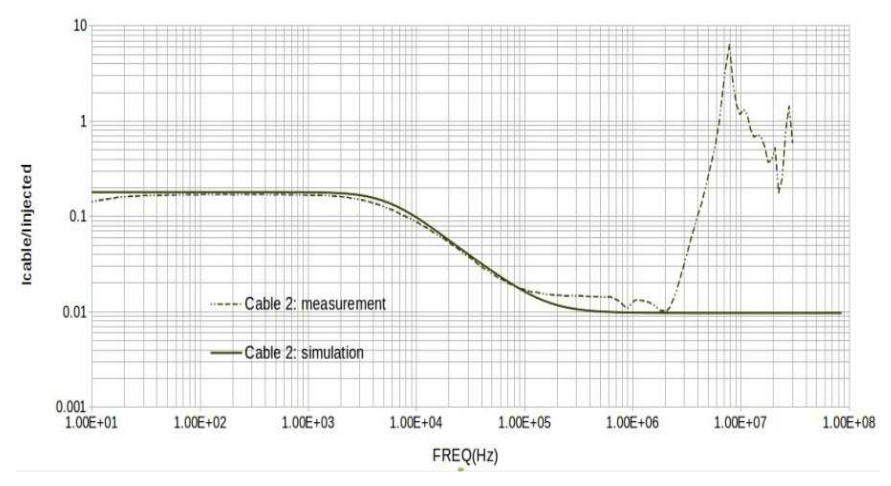

Figure 15. CW analysis of normalized current over cable 2 (see

Figure 11), continuous: simulation, dashed: measurement

Globally, the simulated current flowing over the cables from a lightning injection is in good agreement with measurement (Figures 13, 14, 15). However, beyond $1 \mathrm{MHz}$, it differs due to noise in the measurement chain. The high frequency response of cable $1 \mathrm{C}$ between $100 \mathrm{kHz}$ and $1 \mathrm{MHz}$ can be in better correspondence with measurement if the partitioning is modified.

\subsection{Sensitivity to partitioning on HF response}

The low frequency partitioning can be locally refined (see Figure 16) so that current can flow over the cylinder transversally and feed the cable $1 \mathrm{C}$ with the right amplitude at high frequencies (Figure 17).

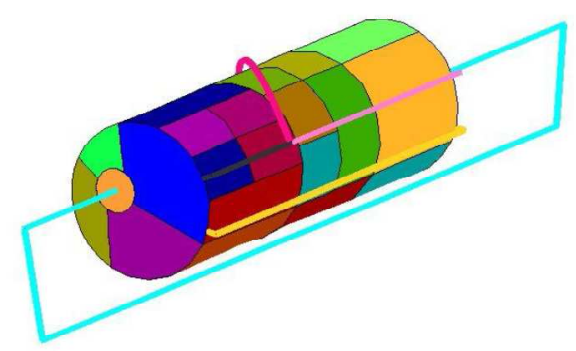

Figure 16. Locally refined partitioning

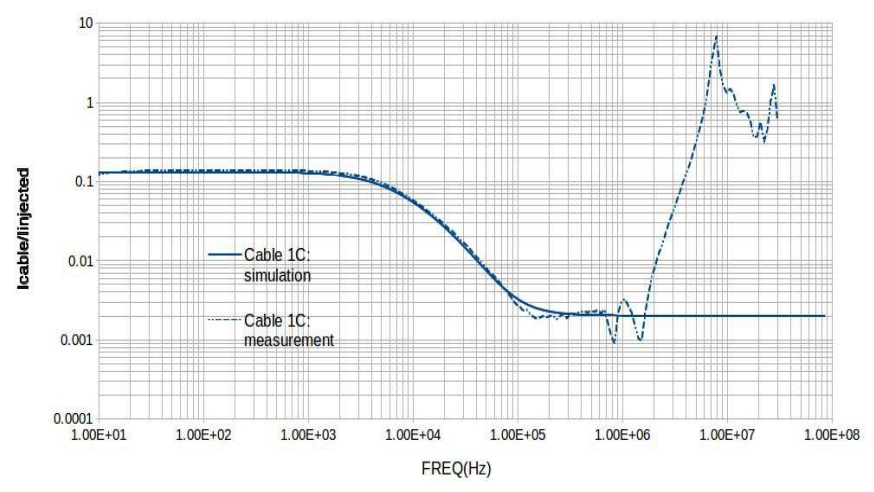

Figure 17. CW analysis of normalized current over cable 1C (see Figure 11), continuous: simulation, dashed: measurement

\section{Conclusion}

In this paper, a new macro model for the quasi-static lightning injection problem has been proposed. It provides the pertinent number of degrees of freedom necessary to reproduce the physical phenomena of lightning. Besides this model, a numerical method has been presented, which includes the analysis of electrical interfaces between conductors, the geometrical surface smoothing for complex structures and the system partitioning on which the high frequency lightning response depends. In order to better fit the transition to this high frequency response, a dedicated model is being implemented which is based on the co-simulation between low frequency current distributions and high frequency ones which account for so-called "proximity effects" in inductive interactions. Finally, the capability of the model to deal with complex geometries will be tested by confronting the simulation with lightning injection on an actual aircraft engine. 


\section{References}

[1] J.-P. Parmantier et al., "Indirect Effects of Lightning on Aircraft and Rotorcraft," Journal Aerospace-Lab, Lightning Hazards to Aircraft and Launchers, Issue 5, pp.20-24, December 2012.

[2] D. Prost et al., "Lightning-Induced Current Simulation Using RL Equivalent Circuit: Application to an Aircraft Subsystem Design", IEEE Trans. Electromagn. Compat., vol. 55, no. 2, pp.378384, April 2013.

[3] L. Knockaert et al. "Generalized Poisson-Neumann Polygonal Basis Functions for the Electromagnetic Simulation of Complex Planar Structures". IEEE Trans. On Microwave Theory and Techniques, 52 (3): 954-961, March 2004.

[4] G. Huiskamp. "Difference Formulas for Surface Laplacian on a Triangulated Surface", Journal of Computational Physics, (95): 477-496, 1991.

[5] F. Andriulli et al. "Hierarchical Bases for Nonhierarchic 3-D Triangular Meshes". IEEE Trans. on Antennas and Propagation, 56(8): 2288-2297, August 2008.

[6] E. B. Rosa. "The Self and Mutual Inductances of Linear Conductors", Bulletin of the Bureau of Standards, 4(2): 301-344, September 1907.

[7] S. Adrian and F. P. Andriulli, "Primal and Dual Graph Haar Bases for the Hierarchical Regularisation of the EFIE on Unstructured Meshes", International Conference on Electromagnetics in Advanced Applications (ICEAA), 2013. 